\title{
Suulisus, kirjalikkus ja digitaalsus kultuuris ja teaduses
}

\author{
Tiiu Jaago \\ Tartu Ülikooli kultuuriteaduste instituudi \\ eesti ja võrdleva rahvaluule osakonna dotsent \\ tiiu.jaago@ut.ee
}

Teesid: Teksti suulise, kirjaliku ja digitaalse esituse teema on jätkuvalt aktuaalne, kuna siin põimuvad nii nende järgnevus kui ka samaaegsus. Senistele uurimustele ja Eesti kultuuriruumi näitele tuginedes vaadeldakse kirjakultuuri arengujooni ja suulise, kirjaliku ning digitaalse esituse vastastikmõjuseoseid.

Märksõnad: kirjakultuuri kujunemine, suulisuse ja kirjalikkuse uuringud

Käesolev teemanumber lähtub 2016. aasta detsembris toimunud Kreutzwaldi päevade 60. ja Eesti-uuringute Tippkeskuse 3. aastakonverentsist "Suuline ja kirjalik kultuuris: põimumised ja põrkumised" (CEES 2016). Ajakirja teemanumbris on kuus artiklit, mis on nii konverentsil arutlusel olnud teemade edasiarendused kui ka teemaga haakuvad käsitlused. Tähelepanu koondub suulise ja kirjaliku väljendusviisi omavahelistele seostele nii 19. sajandi lõpus kui ka tänapäeval; vaadeldakse nii suulise keelevormi süntaksi kui ka digitaalse kommunikatsiooni erijooni; arutletakse suulisuse ja kirjalikkuse tähenduse üle folkloristikas. Kõik artiklid on seotud suulise ja kirjaliku kooseksisteerimise ja omavaheliste põimumiste ning vastasmõju seoste küsimusega. Kuigi suulisuse ja kirjalikkuse teema on kultuuride-ülene, on siinsed artiklid seotud eesti keele ja kultuuriruumiga.

Kirjalikkusest eesti keele ja kultuuri kontekstis kõneldes tuleb arutleda selle üle, mida tähendas eestikeelse teksti lugemine või ka ettelugemine. Eestlaste kirjaoskuse seisukohast on oluline ka see, millise lugemuse taustal kirjutamisvilumus kujunes. Kõneldes eestikeelsete trükiste lugemisest 16.-17. sajandil eeldatakse, et need ei olnud mõeldud mitte niivõrd eestlastele, kuivõrd kohalikele sakslastele, kes eesti kogukondadega kokku puutusid. Jürgen Beyer näiteks väidab, et eestikeelsed ("mittesaksakeelsed") trükised olid ennekõike 
olulised pastoritele, et sealt sobivaid lõike kogudusele ette lugeda: “1680. aastate piiblitõlked ei olnud loomulikult eesti- ja lätikeelse kirjanduse algus. Esimesed tekstid ilmusid juba 16. sajandil. Suuremal hulgal hakati eesti- ja lätikeelseid raamatuid avaldama 1630. aastatest. Esialgu oli tegemist eelkõige pastoritele mõeldud käsiraamatutega (katekismused, perikoobiraamatud, postillid, lauluraamatud)" (Beyer 2014: 281-282). Samas mainib Beyer aabitsate trükkimist, mis kaasnes talurahvakoolide rajamisega 17. sajandi lõpus (vt ka Palli 1998: 14). Kirjakultuuri kujunemise ja kirjaoskuse omandamise seisukohast oli koolide rajamine üks kesksemaid aspekte. Aivar Põldvee nõustub Beyeriga selles osas, et 16. sajandi eestlastel (talurahval) lugemisoskus praktiliselt puudus. 16. ja 17. sajandi vahetusel toimunud sündmusi vahendavatest dokumentidest võib aga siiski leida näiteid, et üksikuid vaimulike tekstide tõlke lugejaid eestlaste seas siiski leidus: "Talupoeg [Veneküla Hans], kes vaidleb oma kirikuõpetajaga usuküsimustes, tunneb huvi, kas Uue Testamendi tõlge langeb kokku saksa omaga, ning võrdleb kirikukäsiraamatute erinevaid versioone, on vaadeldava ajajärgu eesti ajaloos haruldane nähtus, aga mitte päris erandlik [---]. Veel haruldasem oli Käsu Hans oma mõni aasta hiljem kirjutatud nutulauluga, mis erandina ometi ennustas saabuvat uut aega, mil talupoeg mitte ainult ei loe, vaid ka luuletab" (Põldvee 2017: 360). ${ }^{1}$ Põldvee käsitluses tuleb kirjaoskuse levikus kooli osa kõrval esile ka suhtlustasand. Kirjeldades 1693. aastal toimunud Liivimaa kiriku sinodi protokolli, vahendab ta Paistu kirikuõpetaja Andreas Hornungi kaebust talupojast jumalasõna vahendaja vastu. Ilmneb, et talurahva hulgast pärit raamatulugeja saavutas jumalasõna seletamisel kohalikele suurema populaarsuse kui pastor (samas: 360-361). Võib eeldada, et seda võimaldas nimelt tõlkega kaasnevatest kultuurieripäradest möödapääsemine ja eesti keele sügavam tundmine. Sama teemat arendab 18. sajandi valgustusajastuga seoses Thomas Taterka, kasutades keele rahvapärasuse mõistet: kuna keele rahvapärasuse puudumine takistas teabe jõudmist adressaadini, siis on ootuspärane, et valgustajad tegelesid kohalikke keeli puutuva teemaga märkimisväärselt palju. Rahvapärase keelekasutuse kujundamisel on valgustuse üks eesmärke keeleloome, kus tugineti oluliselt rahva suulisele ja poolsuulisele keelele, mitte Euroopas välja kujunenud kirjakultuurile või kirjandusele (Taterka 2014: 41, 45).

Valgustusajastul toimunud murrangud, sh reformid viisid ettelugemise asendumisele lugemisega. Samas ei taganud lugemisoskuse edendamise soov veel seda, et talupoegi oleks ka kirjutama õpetatud. Vaimuliku kirjanduse kõrval said sel ajajärgul oluliseks seadussfääri puudutavad tekstid. Rahvakeelsete õigustekstide avaldamise eesmärk oli selgitada talurahvale õiguskorda, mille tulemusena "[m]ittesaksa maarahvas tehti kirja vahendusel mingis mõttes 
tuttavaks iseendaga - nimelt selle eriomase staatusega õigussubjektina - ja teda julgustati spetsiaalselt selle staatuse üle järele mõtlema“ (Taterka 2014: 33). Ilmaliku kirjavara laienemine, sh perioodika ilmumine ("Lühike Õpetus", 1766-1767) viitab Thomas Taterka seisukoha järgi sellele, et talurahvas nähti lugejat (Taterka 2014: 37). 18. sajandi lõpuks oskas väidetavasti lugeda ligikaudu 50\% ja kirjutada 5\% talurahvast. Otepää kihelkonna personaalraamatutele tuginedes saab rahvastikuajaloolane Heldur Palli täpsustada, et 1765. aastal oskas lugeda 43,8\% ja 1780. aastal 44,5\% külarahvast, kusjuures vanuseti ja sooliselt erines see osakaal märkimisväärselt (Palli 1998: 21). 19. sajandil kasvas lugeda oskajate kõrval jõudsalt ka kirjutada oskajate arv: 1881. aasta rahvaloenduse andmeil oskas nii lugeda kui ka kirjutada 34\% eestlastest ja ainult lugeda 60,9\% (samas: 21-22).

Põige reformatsiooni- ja valgustusajajärgu lugemisteemadesse on sissejuhatuseks Katre Kikase ja Kärri Toomeos-Orglaane artiklitesse, milles käsitletakse 19. sajandi lõpu rahvapärast kirjutamisviisi. Kuidas lugemise najal omandati kirjakeelt olukorras, kus see oli normeerimata ja kus tuli kirja panna nii, kuidas rahvas räägib. Lisaks põimus suulisest ja kirjalikust kultuurist lähtuv mitmetasandilisus ka mitmekeelse keeleruumiga (suuline kõnekeel või murded, uus ja vana kirjaviis ning sellega seotud ühtsust taotlev kirjakeel, aga ka eesti ja vene keele samaaegne kohalolek Setumaal). Täpsemalt vaatleb Katre Kikas kahe Jakob Hurda kirjasaatja, Hans Anton Schultsi ja Jaan Pindi keeleteemalisi sõnavõtte. Mõlemad 19. sajandi keskel sündinud mehed olid kolm talve koolis käinud, ent jätkuvalt oma teadmisi ja oskusi lugemise varal täiendanud. Iseõppimisele tuginevat kirjutamisviisi on Katre Kikas käsitlenud kui rahvapärast kirjalikkust (vastukaaluks ühiskonnas positsioonikamale institutsionaalsele kirjutamisviisile). Autor näitab, et rahvapärase kirjalikkuse kujunemisel mängis tol ajal murdekeele kõrval märkimisväärset rolli ajakirjandus, mis pakkus nii kirja(stiili)näiteid kui ka keeleteemalisi arutlusi.

Ka Kärri Toomeos-Orglaan analüüsib Jakob Hurdale saadetud tekste. Ta vaatleb üksikasjalikult 1887. aastal Hurdale saadetud käsikirja, milles on koos erinevad keeled ja murded (eesti, vene, setu) ja kirjasüsteemid (ladina tähestik, kirillitsa). Nende tekstide kirjutajateks on Stepan Dimitrjev ja munk Arkadi (Andrei Jakovlev) Setumaalt ning Jüri Truusmann. Autor juhib tähelepanu sellele, et kui enamasti on esile toodud tolleaegse Setumaa elanike valdav kirjaoskamatus, siis seda enam väärivad tähelepanu need vähesed, kes kirja teatud eri- ja ajastuomasel viisil valdasid ja kasutasid.

Hurda rahvaluulekogus sisalduv ja valgustusajastusse tagasiviidav arusaam suulisusest ja kirjalikkusest pakub huvi folkloristika ajaloo seisukohast. Tiiu Jaago vaatleb oma artiklis, mil määral on suulisus olnud rahvaluule määravaks 
tunnuseks ja miks see seisukoht 20. sajandi teisel poolel taandus. Ühtlasi küsitakse, kuidas on kujunenud sellised uurimissuunad nagu suuline kirjandus ja suuline ajalugu (oral history) ning mis seos on neil rahvaluule ja rahvaluuleuurimisega. Tuleb esile, et kui folkloristlik suulise kultuuri uurimine kujunes kirjakultuuri vahendusel ja sellest lähtudes, siis suulisuse uuringud eeldavad teadusaladevahelist koostööd.

Kirjaliku ja suulise keele erijooni vaatlevad keeleteadlased Liina Lindström, Maarja-Liisa Pilvik, Helen Plado. Lähtudes murdest kui suulisest keelevormist ja kvantitatiivseid võrdlevaid meetodeid kasutades vaagivad autorid murrete süntaksi eripära üle - see, mis kirjakeeles mõjub veana, ei ole seda murdes. Seda teemat vaadeldakse nimetamiskonstruktsioonide varal (nt 'seda kutsuti teomehest'). Uurimusest joonistuvad välja nii murdepiirid Eestis kui ka vaadeldud keelelise konstruktsiooni seotus murde iseärasustega.

Suuliste ja kirjalike esituste kattumised, ent veelgi enam erijooned tulevad esile Kristel Vilbaste ja Mikk Sarve artiklis Taevaskoja Emalättest. Selles käsitluses põimuvad omavahel ühelt poolt maastik ja teiselt poolt sellega seotud kirjandus, pärimus ning looduskaitse teemaline dokumentatsioon. Kõikidel neil tekstiliikidel on oma osa maastiku ja inimese (kultuuri) seotuse esitlemisel, ent need ei ole alternatiivsed ei teabe sisu, funktsiooni ega meeldejätmise seisukohast.

Suulisuse ja kirjalikkuse mitmetasandilisust, täpsemalt erinevate tekstiliikide, tehnoloogia ning kommunikatsiooniviiside seotust käsitlevad semiootikud Mari-Liis Madisson ja Andreas Ventsel. Kui Emalätte-tekstide võrdlus osutas dialoogi, erimeelsuste ja väitluse võimalikkusele, siis online-tekstide vaatlus osutab näitele, mida iseloomustab piiratud tähendusruum, kus kokkupuude teist laadi ideedega on märkimisväärselt vähene.

Suulisuse ja kirjalikkuse teemalised käsitlused osutavad sellele, et tegemist on ajalooliselt kujunenud ja jätkuvalt kujuneva suhtemustriga. Samas muudab digiajastu ka suulisuse ja kirjalikkuse omavahelist seotust. Kui üldjoontes taandub suulisuse ja kirjalikkuse uurimine teatud vastandusse (nt suulise esituse seotus situatiivse kontekstiga, mis ei iseloomusta kirjalikku teksti; suulise teksti vormellikkus vms), siis veebis esitatu sisaldab nii suulise kui kirjaliku esituse elemente (vt lähemalt nt Mason 1998). John Miles Foley kõrvutab neid kolme. Kõiki kolme esitusviisi iseloomustab tekstiliikide olemasolu ja moodustumine. Erinevused seisnevad aga näiteks teksti seotuses avalikkuse ja autoriõigustega, variaabluse võimalikkuses või selle puudumises, korduvuse ja korratavuse erijoontes, teksti meeles või muul moel alalhoidmises (vt võrdlevat tabelit Foley 2012: 41). Kultuurinäitena võib vaadelda tõsielulugude jutustamist, mis võimaldab nii suulist, kirjalikku kui ka digitaalset esitust, ent 
need tehnoloogiad ei paku täpselt sama tulemust. Jyrki Pöysä eristab suulist ja kirjalikku kui kaht esitusviisi meenutamisolukorra erinevustest lähtudes: "kirjutamine ei ole üksnes privaatne, vaid ka intiimne", samas suuline esitus eeldab publiku kohalolekut (Pöysä 2009: 44-46).

Perepärimuse ja suguvõsauurimise näitel kirjeldab Anne Heimo sotsiaalmeedias vahendatud sõnavõttude teabevahetusele lisanduvat vestluslikkust: teemast innustunud netikasutajad lisavad algatatud teemadele ja lähenemisviisidele omalt poolt uusi ja uusi edasiarendusi (Heimo 2014: 163-164). Tulemuseks on kompaktsete terviklike tekstide asemel ahelpostituste teemakimbud. Digiesituste uuringutes näidatakse, kuidas infotehnoloogia kujundab uusi tekstiloome viise ja vorme, mis omakorda võimaldavad luua varasemate lugude ja tekstiliikide baasil uusi esitusi (Kõiva 2008: 33, 45 jj; Fagerjord 2010; Alleyne 2015: 104). Hoolimata mõningatest piirangutest (nagu salasõna nõue vms) on veebikeskkond kättesaadav igaühele, kes selles osaleda tahab (Foley 2012: 48). Käesolevas ajakirjas esitatud artiklis toovad aga Mari-Liis Madisson ja Andreas Ventsel tähelepanu keskmesse online-suhtluse valikulisuse, mis haakub selliste kontseptsioonidega nagu "vernakulaarne veeb" ja "kajakambri efekt". Mõlemaid kontseptsioone vaadeldakse eesti paremäärmuslaste online-suhtluse näitel. Lähemalt keskendutakse tähendusloome aspektidele, mida kirjeldatakse kui dialoogile vastanduvat, endasse sulguvat autokommunikatiivset suhtlust. Paremäärmusliku online-suhtluse näitel esitletakse selliseid tõlgendusmustreid nagu analoogia, antiteetiline vastandumine, "õigetele" tekstidele orienteeritus. Tähendusloome valikulisus kujundab online-kogukondi, mistõttu muutub see kõigile kättesaadav ja avatud suhtlusruum omakorda piiritletud ruumiks.

Käesolev ajakirjanumber pakub eesti keele ja kultuuri analüüsil põhinevaid vaateid suulise, kirjaliku ja digitaalse esituse sõlmpunktidesse. Käsitlustes kajastuvad nii kultuuriajaloolised aspektid kui ka sellest mõtlemise viisid. Ühtlasi leidub artiklites teema käsitlemiseks sobivaid teoreetilisi kontseptsioone (nt rahvapärane kirjalikkus, autokommunikatsioon) ja näiteid nii kvalitatiivsetest kui ka kvantitatiivsetest uurimismeetoditest. 


\section{Kommentaar}

1 Käsu Hansu nutulaul: viide 1708. aastast pärit 32 salmi sisaldavale luulevormis esitatud "Kaebalaulule Tartu hävitamise puhul", mis on tuntud värsirea "Oh! ma vaene Tardo Liin" järgi (Saareste \& Cederberg 1992: 306-315). Kaebelaulu vanim säilinud koopia 1714. aastast on talletatud Rahvusarhiivis ning on digitaalselt nähtav Rahvusarhiivi kodulehel arhiivikooli rubriigis (Millest jutustab Käsu Hans? http:// www.eha.ee/arhiivikool/index.php?tree_id=32).

\section{Kirjandus}

Alleyne, Brian 2015. Narrative Networks. Storied Approaches in a Digital Age. Los Angeles, London, New Delhi, Singapore, Washington.

Beyer, Jürgen 2014. Mittesaksakeelsed Piiblid sakslaste jaoks? Esimeste läti-, tartu- ja tallinnakeelsete piiblitrükiste kasutamisest. Kaju, Katre (koost). Balti kirjasõna ja kultuurielu valgustusajastu peeglis. Eesti Ajalooarhiivi toimetised. Acta et Commentationes Archivi Historici Estoniae 21 (28). Tartu: Eesti Ajalooarhiiv, lk 248-283.

CEES 2016 = Lukas, Liina \& Roll, Meelis \& Voolaid, Piret (koost) 2016. Suuline ja kirjalik kultuuris: põimumised ja põrkumised. Eesti-uuringute Tippkeskuse ja Kreutzwaldi päevade 60. konverents. 12. ja 13. detsembril 2016 Eesti Kirjandusmuuseumis. Ajakava ja ettekannete kokkuvõtted. Tartu: EKM Teaduskirjastus (https://www.folklore.ee/ CEES/teesid2016.pdf - 18. jaanuar 2018).

Fagerjord, Anders 2010. After Convergence. YouTube and Remix Culture. Hunsinger, Jeremy \& Klastrup, Lisgeth \& Allen, Matthew (toim). International Handbook of Internet Research. Dordrecht \& Heidelberg \& London \& New York: Springer, lk 187-200 (doi: 10.1007/978-1-4020-9789-8_11).

Foley, John Miles 2012. Oral Tradition and the Internet: Pathways of the Mind. Urbana \& Cicago \& Springfield: University of Illinois Press.

Heimo, Anne 2014. Pereajalugu internetiajastul: diasporaa-genealoogia ja jätkuv ajalookirjutusprotsess. Mäetagused 56, lk 155-180 (doi: 10.7592/MT2014.56.heimo).

Kõiva, Mare 2008. Kahe kultuuri vahel. Virtuaalne väliseesti kogukond. Labi, Kanni (toim). Paar sammukest 24. Eesti Kirjandusmuuseumi aastaraamat 2007, Tartu: EKM Teaduskirjastus, lk 31-59.

Mason, Bruce Lionel 1998. E-Texts: The Orality and Literacy Issue Revisited. Oral Tradition 13 (2), lk 306-329.

Millest jutustab Käsu Hans? = Rahvusarhiiv, Arhiivikool - peatuspaik ajaloohuvilistele (http://www.eha.ee/arhiivikool/index.php?tree_id=32 - 19. jaanuar 2018).

Palli, Heldur 1998. Eesti rahvastiku ajaloo lühiülevaade. Tallinn: Sisekaitseakadeemia. 
Põldvee, Aivar 2017. Mittesaksakeelsed Piiblid mittesakslaste jaoks. Asitõendeid lugemise ajaloost. Kaju, Katre (koost). Kroonikast epitaafini. Eesti- ja Liivimaa varauusaegsest haridus- ja kultuurielust. Rahvusarhiivi toimetised. Acta et Commentationes Archivi Nationalis Estoniae 1 (32). Tartu: Rahvusarhiiv, lk 349-375.

Pöysä, Jyrki 2009. Kogumisvõistlused pärimusliku ajaloo uurimises. Mäetagused 43, lk 39-60 (doi: 10.7592/MT2009.43.poysa).

Saareste, Albert \& Cederberg, Arno Rafael 1992 [1925-1931]. Valimik eesti kirjakeele vanemaid mälestisi a. 1524-1739. Faksiimileväljaanne. Tartu: Tartu Ülikool.

Taterka, Thomas 2014. Rahvas ja rahvad. Lätlastele ja eestlastele suunatud Saksa rahvavalgustuse põhijooni Vene Läänemere provintsides Liivi-, Kura- ja Eestimaal. Kaju, Katre (koost). Balti kirjasõna ja kultuurielu valgustusajastu peeglis. Eesti Ajalooarhiivi toimetised. Acta et Commentationes Archivi Historici Estoniae 21 (28). Tartu: Eesti Ajalooarhiiv, lk 17-79.

\section{Summary}

\section{Orality, literacy, and digitality in culture and research}

\section{Tiiu Jaago}

Assistant Professor

Department of Estonian and Comparative Folklore

Institute of Cultural Research, University of Tartu

tiiu.jaago@ut.ee

The introductory overview provides a more general framework for understanding the articles published in this special issue. The discussions presented from the folkloristic point of view dwell upon the writing practices followed by Jakob Hurt's correspondents in the late 19th century. The authors highlight the multilevelness of the writing experience and style manifest in the contributions of Hurt's correspondents, which draw partly either on oral speech, reading, dialects, or unified spelling system. Also, in this period folklore was regarded as a phenomenon of oral culture, and therefore folklore collectors eliminated the idea of these stories being related to written culture. However, this approach did not correspond to reality. According to the 1881 census data, $34 \%$ of Estonians could both read and write, and $60.9 \%$ could only read.

For an easier understanding of this situation in a historical perspective, this introductory overview presents, drawing on history research, the development features of Estonian peasants' writing culture in the Reformation and Enlightenment eras (16th18th cc.) and data about literacy in 19th-century Estonia. It is shown how Estonianlanguage writing turned from a means of communication (local Germans needed Estonian-language texts to communicate with the peasantry) into a language of education. It is also possible to follow how different information and diverse spheres of culture are related to either oral or written texts (e.g., religious and legal literature, which differed 
from oral lore based on experience). Further studies into orality and literacy discuss their dissimilarities on both linguistic and communicative levels. Late 20th-century research, however, moved to studying the connections between orality and literacy in comparison to digital presentations. On the one hand, scholars discuss the issues of environmental influence on text creation, on the other hand, the novel ways and boundaries of communication spaces. 